\title{
Identification and Counting of Asbestos and Non-Asbestos Fibers in an Automobile Brake Manufacturing Industry
}

\author{
Hossein Marioryad ${ }^{1}$, Hossein Kakooei ${ }^{2 *}$ and Mahdieh Bakhshandeh ${ }^{3}$
}

${ }^{1}$ Department of Occupational Health, Yasuj University of Medical Sciences, Iran

${ }^{2}$ Department of Occupational Health, Tehran University of Medical Sciences, Iran

${ }^{3}$ Department of Health, Safety and Environment Sciences, University of Science and Research Branch Islamic Azad University, Iran

\begin{abstract}
This study was performed to identify and count both asbestos and non-asbestos fibers during brake manufacture in Iran. A total of 56 respiratory air samples of personnel were measured by phase-contrast microscopy (PCM) and scanning electron microscopy (SEM). The fiber type and its chemical composition were also evaluated by SEM and energy-dispersive X-ray analysis (EDX). Monitoring of total fiber levels demonstrated that its ranges are from 0.23 to $1.50 \mathrm{PCM} f / \mathrm{ml}$. The geometric mean and standard deviation of the airborne asbestos and non-asbestos fiber concentrations were $0.22(1.61)$ and $0.32(1.61) \mathrm{SEM} \mathrm{f} / \mathrm{ml}$ respectively. The observed asbestos fiber concentrations in many processes were higher than the threshold limit value (TLV) which is proposed by American Conference of Governmental Industrial Hygienists (ACGIH), as equal as $0.1 \mathrm{f} / \mathrm{ml}$. Based on these findings, the geometric means of the non-asbestos concentrations were considerably lower than TLV of the ACGIH which is $1 \mathrm{f} / \mathrm{ml}$. The SEM data exhibited that fibrous particle consists of chrysotile $(40 \%)$ and rock wool $(60 \%)$. It can be concluded that more than $50 \%$ of airborne fibers inhaled by the workers were rock woo with fibers greater than $1 \mu \mathrm{m}$ in diameter. For evaluation of airborne fibers, the PCM method was not able to detect the fibers lower than 0.25 micrometer. This study demonstrated that SEM technique methods are essential elements for accurate characterization of mineral dusts, particularly when dealing with large number of samples.
\end{abstract}

Keywords: Asbestos; Non-asbestos; Rock wool; SEM; PCM

\section{Introduction}

The six fibrous silicates, with length $>5 \mu \mathrm{m}$, diameter $<3 \mu \mathrm{m}$, aspect ratio $>3: 1$, belong to the asbestos group (chrysotile, crocidolite, tremolite, actinolite, amosite and anthophyllite) in the industrial environment have become a subject of great concern due to their effects on worker health [1,2]. Moreover, some of fine mineral fibers including glass wool and ceramic fibers are able to crystallize with fibrous habit and epidemiological evidence of mesothelioma clusters have been associated also to low level exposure to non-asbestos fibers $[3,4]$. The International Agency for Research on Cancer (IARC) has classified glass and ceramic fibers as group $2 \mathrm{~B}$, possibly carcinogenic to humans. Rock, glass, and slag wools as group 3, was not classified as carcinogen to humans [5]. Since 1960, it was evident that asbestos was a serious public health hazard that could cause asbestosis, lung cancer, and mesothelioma $[6,7,8]$. Asbestos fibers especially serpentine group (chrysotile) was a primary component of brake in car and trucks from early 1900 s to the 1980 s $[9,10]$. The chrysotile asbestos contents of the automobile brake and clutches usually ranged from 35 to $65 \%$ [11,2]. As a result, industrial use of asbestos in friction materials has been banned by many countries, whereas non-asbestos fibers such as rock and glass wool are continuously utilized extensively in automobile brakes and clutches [12]. The current legislation does ban the use of chrysotile asbestos in automobile brake and clutch manufacturing industry of Iran. Approximately 55,000 tons per year have been imported in the last 10 years, and more than $5 \%$ of that is being used in automobile brake and clutch manufacturing [2]. The American Conference of Governmental Industrial Hygienist (ACGIH) threshold limit values (TLV) for respirable asbestos and synthetic vitreous fibers (rock, glass and slag wools) are 0.1 and $1 \mathrm{f} / \mathrm{ml}$, respectively [13]. Three factors including morphology, composition and optical properties of fibers are important in asbestos and non-asbestos fibers assessment. The standard method for determining occupational exposure to asbestos in most countries is the PCM method $[8,14]$. Although this method is an appropriate index of exposure in occupational setting, but its counting scheme only able to determine total fibers concentration not to identify fibers type $[15,16,8]$. Therefore, to overcome these limitations, electron microscopy techniques can be used. In the current study, SEM method have been used to determine the concentration, size and type of asbestos and non-asbestos fibers [17,7,8]. The objective of this study was to determine occupational exposure to airborne asbestos and rock wool during brake manufacturing by PCM and SEM in a developing country. We also sought to characterize asbestos and non-asbestos subtypes, based on evaluations of raw materials and airborne samples.

\section{Experimental Procedure}

\section{Profile of research field}

This study was performed in an automobile brake manufacturing industry in Iran in 2010. The factory initiated its product since 1960s, and chrysotile asbestos is the main constituent in the friction products. It is comparatively a large company in the brake lining manufacturing plant. A total of 220 workers with a mean age of 25 years and mean employment length of 13 years exist. The fine mineral fibers such as rock wool have been used extensively in the factory as brake lining with the emergence of asbestos-free products. Other types of amphibole asbestos, i.e. crocidolite and amosite were not used in the plant. In this plant, the friction materials are manufactured by dry process. The main process consists of: feeding of raw materials, milling and mixing, baking, bevel and drilling, cutting, grinding, welding as well as finishing. In the manufacture process after weighting and mixing of asbestos, rock wool and other raw materials such as ferrous oxide, carbon black, graphite,

*Corresponding author: Hossein Kakooei, Department of Occupational Health School of Public Health, Tehran University of Medical Sciences, Tehran, Iran, Tel: +98 21 88951390; Fax: + 9821 88954781; E-mail: hkakooei@sina.tums.ac.ir; kakooei@gmail.com

Received March 26, 2012; Accepted April 28, 2012; Published April 30, 2012

Citation: Marioryad H, Kakooei H, Bakhshandeh M (2012) Identification and Counting of Asbestos and Non-Asbestos Fibers in an Automobile Brake Manufacturing Industry. J Environ Anal Toxicol 2:139. doi:10.4172/21610525.1000139

Copyright: (c) 2012 Marioryad $\mathrm{H}$, et al. This is an open-access article distributed under the terms of the Creative Commons Attribution License, which permits unrestricted use, distribution, and reproduction in any medium, provided the original author and source are credited. 
lead, resin, talc the compound materials are charged into molds process and brake lining and clutches are produced. Finally, production requires multiple finishing processes such as beveling, cutting, drilling, welding and grinding.

\section{Sampling and analysis}

Fifty-six respiratory air samples were collected from different processes in the plant. The samples were collected and then were mixed on cellulose ester (MCE) filter membranes with support pads, using an open-face filter holder with a 50 - $\mathrm{mm}$ conductive extension cowl. Sampling was performed at a flow rate of $1.7 \mathrm{l} / \mathrm{min}$ using a personal sampling pump (Model Number 224-PCMTX8; SKC-UK). The duration of personal sampling for airborne asbestos was $45 \mathrm{~min}$. One-half of each filter examined was mounted on a glass slide $(75 \times$ $25 \mathrm{~mm}$ ) and analyzed according to National Institute for Occupational Safety and Health (NIOSH) method 7400 (NIOSH 1989). Asbestos and non-asbestos fibers counted by PCM at $400 \times$ magnification using a Walton-Beckett graticule (Type G-22). A fiber was defined as any particle greater than $5 \mu \mathrm{m}$ in length and having at least a 3:1 aspect ratio. Another portion of the $25 \mathrm{~mm}$ diameter filter was prepared and analyzed according to the SEM method detection limit $0.4 \mathrm{f} / \mathrm{ml}$ specified by the International Organization for Standardization (ISO 2002). SEM (model WEGA/TESCAN, Czech Republic) and energydispersive X-ray analysis (EDXA) was used to identify fiber type during the analysis. Raw materials (asbestos and rock wool) were analyzed by SEM.

\section{Data analysis}

Descriptive statistics were used for PCM measurements of the asbestos and non-asbestos fiber concentrations using SPSS software for windows. The mean fiber concentrations are presented as geometric means. Analytical sensitivity limits were estimated based on the NIOSH 7400 method [15]. The ratios of asbestos to total fibers (asbestos and non-asbestos fibers) were based on SEM fiber counts for the same filters from which the PCM fiber counts were obtained. The 8-h threshold limit value-time weighted average (TLV-TWA) airborne asbestos concentrations were calculated from the consecutive 45-min sample obtained from the breathing zone of the worker using the following equations, respectively:

$$
\begin{aligned}
& \left(\mathrm{C}_{1} \times \mathrm{t}_{1}\right) 45 \mathrm{~min} \\
& \left(\mathrm{C}_{1} \times \mathrm{t}_{1}\right) 480 \mathrm{~min}
\end{aligned}
$$

Where $\mathrm{C}_{1}$ is the average airborne concentration of fibers $(\mathrm{f} / \mathrm{ml})$ for the breathing zone for each of sampling segments and $t_{1}$ is the duration of the task. For the 8-h TWA-TLV calculation, the mean of the measured background values was assumed to be present for the remaining $8 \mathrm{~h}$ of the workday.

\section{Results and Discussion}

\section{Asbestos and non- asbestos fiber concentrations}

Table 1 shows the airborne asbestos and total fiber concentrations by processes. The confidence interval of different situation of exposure is shown in Figure 1. The highest and lowest geometric mean (GM) concentrations of asbestos $(0.38 \pm 1.29 \mathrm{SEM} \mathrm{f} / \mathrm{ml}$ and $0.14 \pm 1.28 \mathrm{SEM}$ $\mathrm{f} / \mathrm{ml}$ ) were found in connection with the feeding of raw materials and baking process, respectively. All of the workers involved in the process were exposed to airborne asbestos higher than the TLV proposed by ACGIH, $(0.1 \mathrm{f} / \mathrm{ml})$. The GM values and confidence interval of airborne rock wool concentrations in the personal samples are shown in Table 1 and Figure 1. From the results, it can be concluded that the GM values of airborne rock wool in the personal samples was $0.32 \mathrm{SEM} \mathrm{f} / \mathrm{ml}$, which is considerably lower than the TLV of $1 \mathrm{f} / \mathrm{ml}$ recommended for occupational exposure to rock wool by the ACGIH [13]. None of the non-asbestos fiber concentrations exceeded than the TLV. As mentioned above, around 3-4\% of world's chrysotile asbestos produced [7], are being used in Iran. This study confirms that brake factory workers experience the higher occupational exposure to airborne asbestos in all of the processes [14]. Recent study reported that mean asbestos concentrations during the process of brake lining manufacture averaged $0.87 \mathrm{PCM} \mathrm{f} / \mathrm{ml}$ [14], which is higher than the figures we found in our study [2]. In general, in the current study, the levels of airborne asbestos, non-asbestos and total fiber concentrations

\begin{tabular}{|c|c|c|c|c|}
\hline \multirow{2}{*}{ Process } & \multirow{2}{*}{$\mathbf{N}$} & \multicolumn{3}{|c|}{ fiber concentrations (f/ml) -GM(GSD) -Range } \\
\hline & & Total a & Asbestos ${ }^{b}$ & Rock wool c \\
\hline Feeding of raw material & 12 & $\begin{array}{l}0.96(1.29) \\
0.71-1.50\end{array}$ & $\begin{array}{l}0.38(1.29) \\
0.28-0.60\end{array}$ & $\begin{array}{l}0.58(1.29) \\
0.43-0.90\end{array}$ \\
\hline Milling \& mixing & 8 & $\begin{array}{l}0.54(1.61) \\
0.30-1.10\end{array}$ & $\begin{array}{l}0.22(1.61) \\
0.12-0.44\end{array}$ & $\begin{array}{l}0.32(1.61) \\
0.18-0.66\end{array}$ \\
\hline Baking processes & 10 & $\begin{array}{l}0.36(1.29) \\
0.25-0.53\end{array}$ & $\begin{array}{l}0.14(1.28) \\
0.10-0.21\end{array}$ & $\begin{array}{l}0.21(1.30) \\
0.15-0.32\end{array}$ \\
\hline Drilling \& beveling & 10 & $\begin{array}{l}0.55(1.63) \\
0.27-1.02\end{array}$ & $\begin{array}{l}0.22(1.63) \\
0.11-0.41\end{array}$ & $\begin{array}{l}0.33(1.63) \\
0.16-0.61\end{array}$ \\
\hline Cutting & 8 & $\begin{array}{l}0.56(1.21) \\
0.43-0.76\end{array}$ & $\begin{array}{l}0.23(1.21) \\
0.17-0.30\end{array}$ & $\begin{array}{l}0.33(1.21) \\
0.26-0.46\end{array}$ \\
\hline Grinding \& finishing & 8 & $\begin{array}{l}0.38(1.30) \\
0.23-0.48\end{array}$ & $\begin{array}{l}0.16(1.30) \\
0.09-0.19\end{array}$ & $\begin{array}{l}0.22(1.30) \\
0.14-0.29\end{array}$ \\
\hline Total & 56 & $\begin{array}{l}0.54(1.61) \\
0.23-1.50\end{array}$ & $\begin{array}{l}0.22(1.61) \\
0.09-0.60\end{array}$ & $\begin{array}{l}0.32(1.62) \\
0.14-0.90\end{array}$ \\
\hline
\end{tabular}
estimated in the workplace environment (0.22 SEM f/ml; 0.32 SEM

Table 1: Fiber concentrations during automobile brake manufacture operation. 
Citation: Marioryad H, Kakooei H, Bakhshandeh M (2012) Identification and Counting of Asbestos and Non-Asbestos Fibers in an Automobile Brake Manufacturing Industry. J Environ Anal Toxicol 2:139. doi:10.4172/2161-0525.1000139

Page 3 of 5

$\mathrm{f} / \mathrm{ml} ; 0.54 \mathrm{PCM} \mathrm{f} / \mathrm{ml}$ ) differ from those reported by previous studies $[14,2]$. Furthermore, this study also confirms that the airborne fibers in the process were mainly non-asbestos. Of the total SEM fibers, about $40 \%$ were confirmed as asbestos. The brakes used in the factory contained $30-50 \%$ fibrous raw material by weight. Although chrysotile asbestos was used to manufacture asbestos-containing automobile brake in the factory. It has been known that the airborne total fibers contained amounts of rock wool fibers. This finding is potentially quite important as the weight of evidence indicates that non-asbestos fiber such as rock wool is less potent than chrysotile asbestos [5]. It should be emphasized that in the PCM method, there are some limitations in occupational settings, difficulties in the exact distinction between asbestos and non-asbestos fibers are likely to lead to overestimations, and there are also difficulties in counting ultrafine fibers with diameters less than $0.2 \mu \mathrm{m}[18,8]$. The alternative method of analyzing airborne asbestos and non-asbestos, which may overcome these problems, using SEM, however this method has not been used for analyzing airborne fibers in occupational or non-occupational environments in Iran [8].

\section{Fiber type and morphology}

Fiber size and morphology were assessed for the personal samples collected during the brake manufacturing activities. Figure 2a present image of asbestos and rock wool airborne fibers obtained using conventional SEM with a gold evaporation coating. The images reveal chemical composition of the fibers. It was analyzed using energydispersive spectrometry (EDS) (Figures $2 \mathrm{~b}$ and 2c). Figures 3 and 4 show the SEM image and EDS spectrum of the raw asbestos and rock wool, which was used in the factory. EDX diagram of chrysotile and rock wool (Figures 3 and 4 ) shows the chemical analysis and the ratio of magnesium to silica $(\mathrm{Mg} / \mathrm{Si} 1.41)$ and $(0.30)$, respectively. Chrysotile usually is rich in magnesium oxide (40-50\%), while rock wool contains large amounts of aluminum (30-40\%) and is low in their content of magnesium oxide (5-10\%). When all data and information are considered in the EDS spectrum of the airborne asbestos samples, the results indicated that the fibrous particles in the workplace environment consisted of chrysotile (40\%) and rock wool (60\%). The size (length and
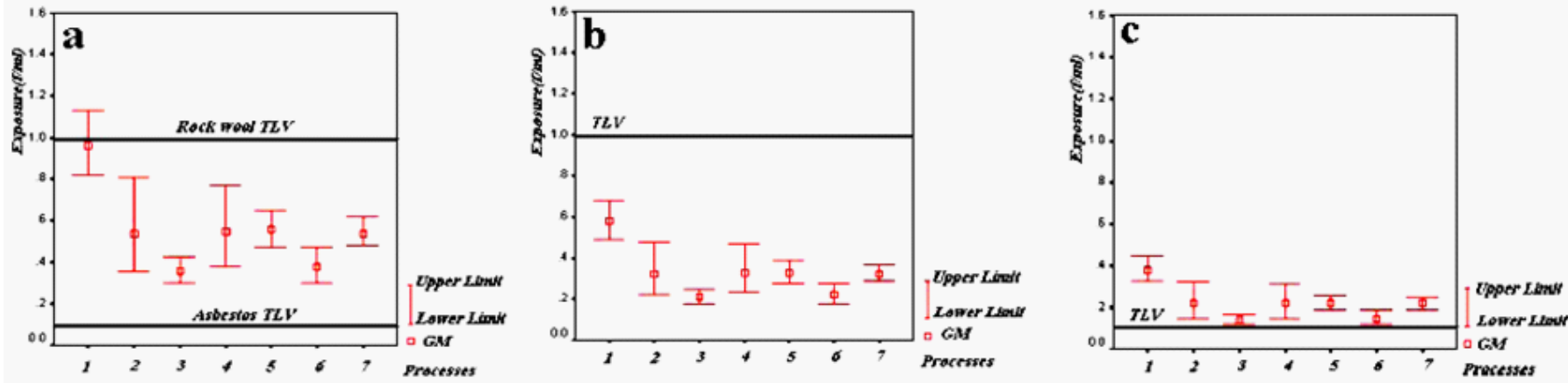

a; Total fibers, b; Rock wool fibers, c; Chrysotile fibers.

*Processes ( $1=$ Feeding of Raw Material, $2=$ Milling \& mixing, 3= Baking processes, $4=$ Drilling \& beveling, $5=$ Cutting, $6=$ Grinding \& finishing, $7=$ Total)

Figure 1: Confidence interval of airborne fiber concentration in different workstations of brake and clutch manufacturing factory.
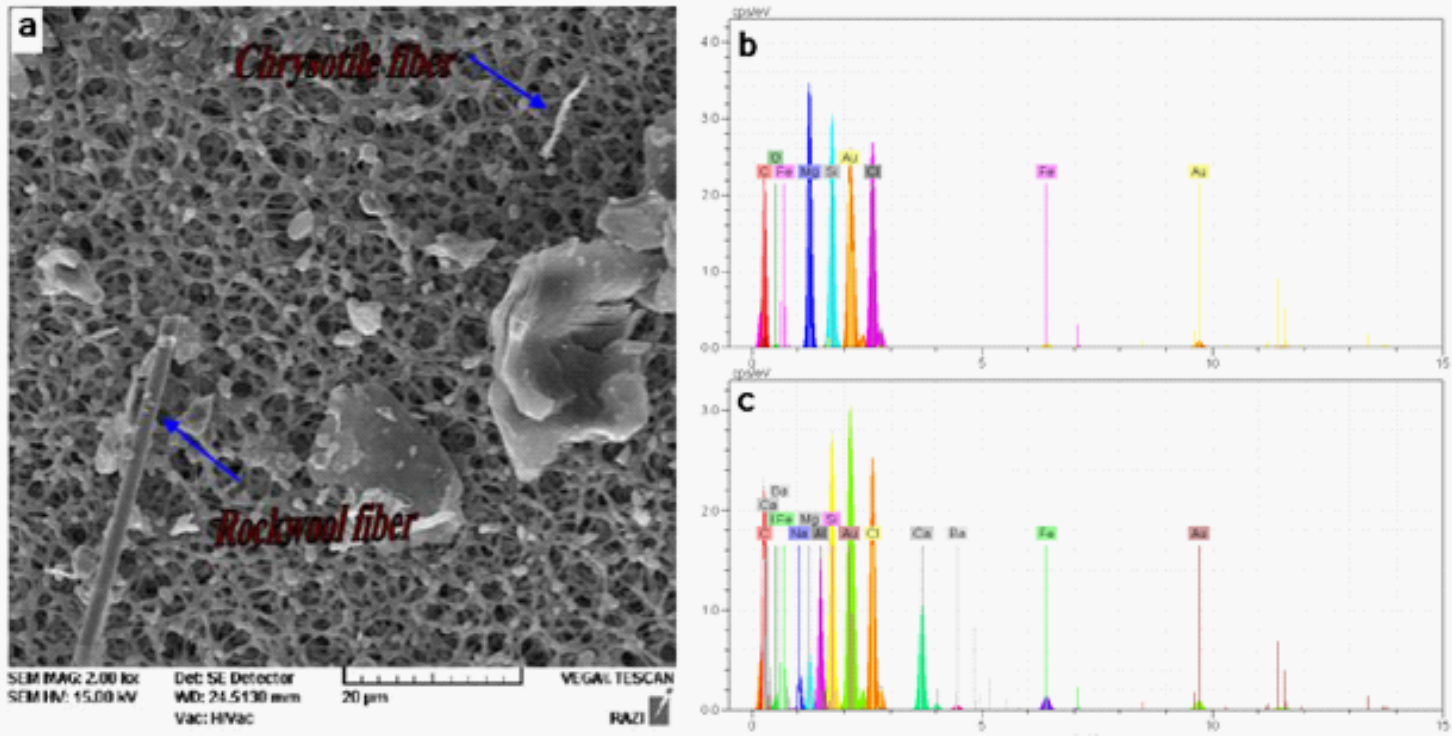

Figure 2: a) SEM image of airborne Chrysotile and Rock wool, Magnification 2000x, b) EDS spectrum of Chrysotile, c) EDS spectrum of Rock wool. 
Citation: Marioryad H, Kakooei H, Bakhshandeh M (2012) Identification and Counting of Asbestos and Non-Asbestos Fibers in an Automobile Brake Manufacturing Industry. J Environ Anal Toxicol 2:139. doi:10.4172/2161-0525.1000139
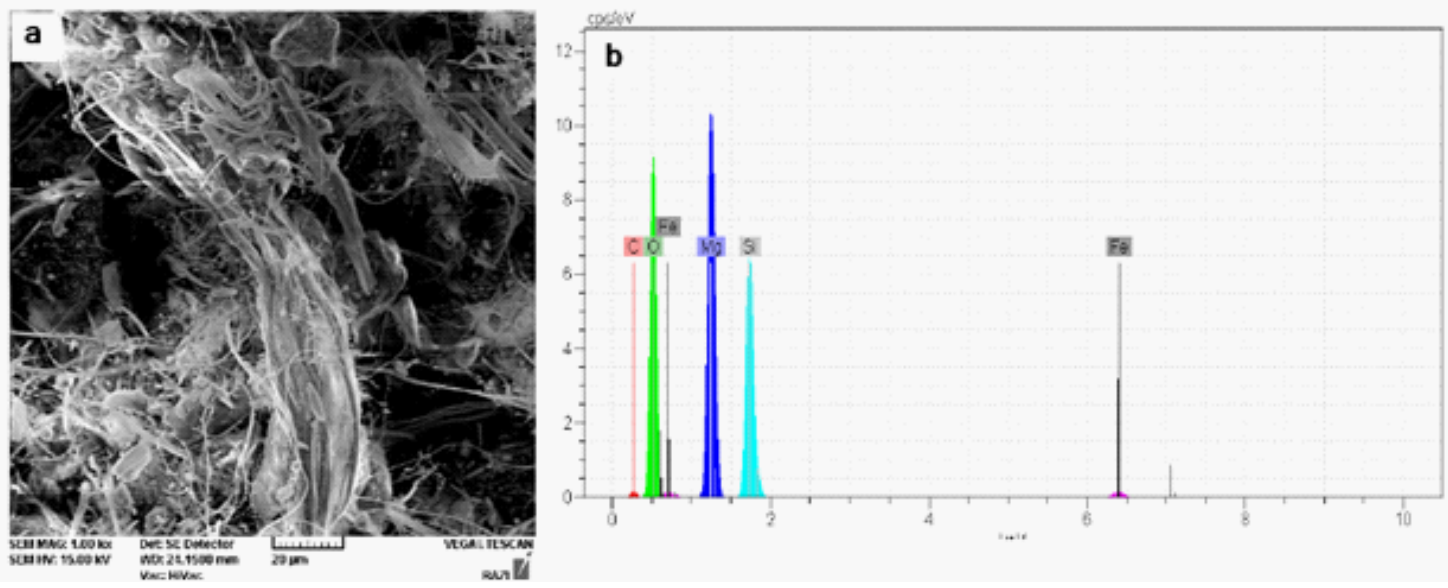

Figure 3: a) SEM image of the raw Chrysotile, b) EDS spectrum of Chrysotile Magnification, 1000x.
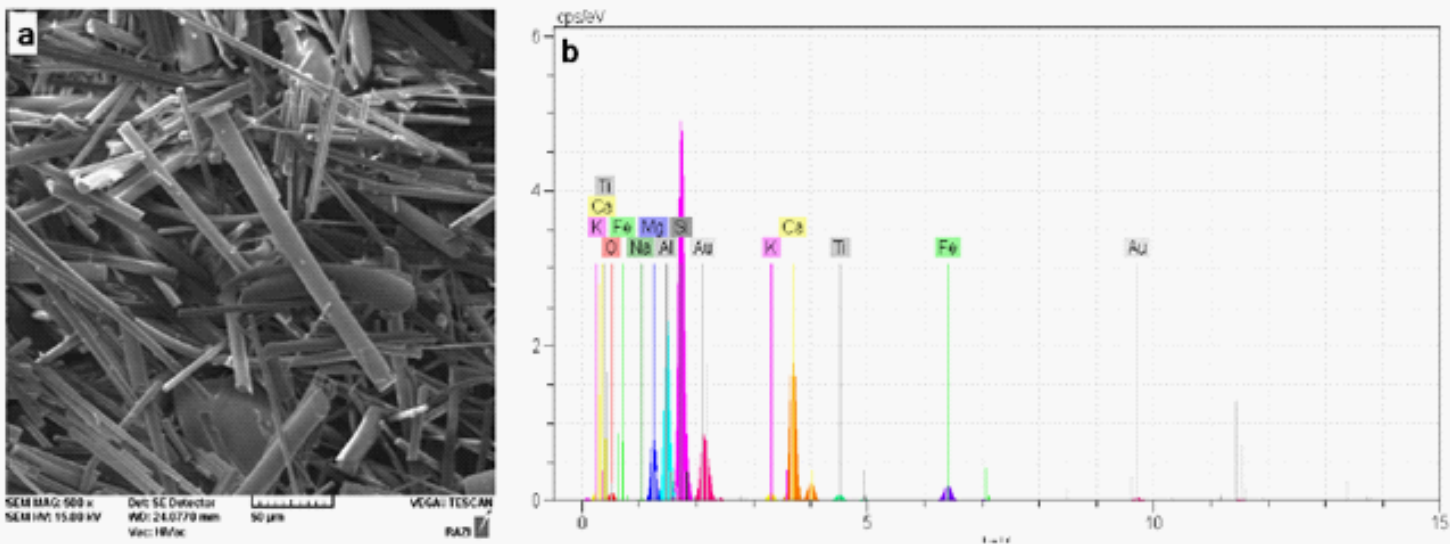

Figure 4: a) SEM image of the raw Rock wool, b) EDS spectrum of Rock wool Magnification, 500×.

diameter) of an asbestos fiber appears to be one of the most important variables of its toxicity. The diameter of the chrysotile fibers was mostly smaller than that of the rock wool fibers (Figures 1 and 3).

As noted above, the SEM analysis revealed that the fibrous particle in the workplace environment consisted of chrysotile (40\%) and rock wool (60\%). As shown in Figure. 2, the SEM and chemical analysis of airborne fibers showed several morphologies, chemical content compatible with the chrysotile and rock wool series with some evidence of magnesium oxide, silica, and aluminum content. It should be noted that chrysotile contains more magnesium oxide (50-60\%), whereas in rock wool, more magnesium is replaced by aluminum (30-40\%). The chrysotile fibers are usually curved, in contrast to the straight morphometry of the rock wool. Considering that raw material consumptions in the factory contain chrysotile asbestos and mineral wool, our results strongly suggested that the PCM method are likely to lead to overestimations (Table 1).

\section{Conclusion}

In conclusion, because the PCM method has some limitations with regard to airborne fiber analysis, the use of microscopic methods other than PCM can be used to improve the techniques used presently. The results of this study have highlighted that according to PCM method, the GM values of total fibers in $100 \%$ of the processes were found to be above the TLV. In contrast, due to SEM method the results would indicate that the fibrous particles in the workplace environment consisted of chrysotile and rock wool. None of the non-asbestos fiber concentrations exceeded the TLV. It can be also concluded that the consumption of mineral wools have special impact for the high airborne rock wool levels in the workplace environment. Despite finding of exposure in differ to excess of ACGIH recommendations, it is unknown if these exposures have any potential health consequences for exposed workers. More research is needed to improve the characterization of occupational exposure by asbestos and non-asbestos fibers in a variety of industries.

\section{Acknowledgments}

This study was founded and supported by Tehran University of Medical Sciences (TUMS). The authors declare that there is no conflict of interests.

\section{References}

1. Verma DK, Clark NE (1995) Relationship between phase contrast microscopy and transmission electron microscopy results of samples from occupational exposure to airborne chrysotile asbestos. Am Ind Hyg Assoc J 56: 866-873.

2. Kakooei $\mathrm{H}$, Marioryad $\mathrm{H}$ (2010) Evaluation of exposure to the airborne asbestos in an automobile brake and clutch manufacturing industry in Iran. Regul Toxico Pharmacol 56: 143-147. 
Citation: Marioryad H, Kakooei H, Bakhshandeh M (2012) Identification and Counting of Asbestos and Non-Asbestos Fibers in an Automobile Brake Manufacturing Industry. J Environ Anal Toxicol 2:139. doi:10.4172/2161-0525.1000139

Page 5 of 5

3. Skinner HCW, Ross M, Frondel C (1988) Asbestos and other fibrous minerals: Mineralogy, crystal chemistry, and health effects. Oxford University Press, New York.

4. Hillerdal G (1999) Mesothelioma: cases associated with non-occupational and low dose exposure. Occup Environ Med 56: 505-513.

5. IARK (International Agency for Research on Cancer) Man-made mineral fibers (2002) IARK monograph of evaluation of carcinogenic risks to human.

6. Sulivan JB, Krieger GR (2001) Clinical Environmental Health and Toxic Exposure. Lippincott, Williams \& Wilkins, USA

7. Panahi D, Kakooei H, Marioryad H, Mehrdad R, Golhosseini M (2011) Evaluation of exposure to the airborne asbestos in an asbestos cement sheet manufacyuring industry in Iran. Environ Monit Assess 178: 449-454.

8. Marioryad H, Kakooei H, Shahtaheri SJ, Yunesian M, Azam K (2011) Assessment of airborne asbestos exposure at an asbestos cement sheet and pipe factory in Iran. Regul Toxicol Pharmacol 60: 200-205.

9. Berry G, Newhous ML (1983) Mortality of workers manufacturing friction material using asbestos. Br.J.Ind.Med 40: 1-7.

10. Kakooei H, Hormozy M, Marioryad H (2011) Evaluation of asbestos exposure during brake repair and replacement. Ind Health 49: 374-380.
11. Anderson AE, Gealer RL, McCune, RC (1973) Asbestos emission from brake dynamometer test. Ford Motor Company Scientific Research Staff, M Technical Report No. SR 64-73.

12. Richardson DB (2009) Lung cancer in chrysotile asbestos workers: analyses based on the two-stage clonal expansion model. Cancer Cause Control 20 917-923.

13. American Conference of Governmental Industrial Hygienist (ACGIH) (2010) Threshold Limit Values for chemical substances, ACGIH, Cincinnati.

14. Kakooei H, Sameti M, Kakooei AA (2007) Asbestos exposure during routine brake lining manufacture. Ind Health 45: 787-792.

15. National Institute for Occupational Safety and Health (NIOSH), Method 7400 Fibers (1998) In: NIOSH manual of analytical method. 3th ED., U.S. Department of Health, Education and Welfare, Cincinnati.

16. Occupational Safety and Health Administration (OSHA), Asbestos in air (1997) OSHA method ID-160.

17. Eypert-Blaison C, Veissiere S, Rastoix O, Kauffer E (2010) Comparison of direct and indirect methods of measuring airborne chrysotile fiber concentration. Ann Occup Hyg 54: 55-67.

18. Harper M, Bartolucci A (2003) Preparation and examination of proposed consensus reference standards for fiber counting. AlHA J (Fairfax, Va) 64: 283287 